\title{
Role of Treadmill Test in Detection of Asymptomatic Coronary Artery Disease in Patients with Type 2 Diabetes Mellitus
}

\author{
Madhur Sharma $^{1 *}$, Vipin Patel ${ }^{1}$, Snehal Mishra ${ }^{1}$, S. Inamdar ${ }^{2}$, R.K Jha
}

${ }_{1}^{1}$ Junior Resident, Department of General Medicine, SAMC\&PGI, Indore (453555), M.P, India
${ }^{2}$ Professor, Departmen of General Medicine, SAMC\&PGI, Indore (453555), M.P, India
${ }^{3}$ Professor \& Head, Departmen of General Medicine, SAMC\&PGI, Indore (453555), M.P, India

DOI: $10.36347 /$ sjams.2021.v09i04.003

| Received: 05.03.2021 | Accepted: 24.03.2021 | Published: 02.04.2021

*Corresponding author: Madhur Sharma

Background: Coronary artery disease (CAD) remains asymptomatic in many patients with Type 2 Diabetes Mellitus $\left(\mathrm{T}_{2} \mathrm{DM}\right)$ making its diagnosis challenging. There is high incidence of silent myocardial ischemia in diabetic patients. This study was carried out with the aim of determining the prevalence of asymptomatic CAD in diabetic patients using treadmill test and study the relationship between duration of $\mathrm{T}_{2} \mathrm{DM}$, glycemic control and dyslipidemia with Treadmill Test (TMT) changes. Method: This observational study which included 75 patients was conducted at SAMC \& PGI, Indore. All the patients above the age of 18 years who had been diagnosed with $\mathrm{T}_{2} \mathrm{DM}$ and were found to have no clinical, electrocardiographic or echocardiographic evidence of CAD were included in the study. Results: Fifty-seven $(76 \%)$ of the patients were men and $18(24 \%)$ were women with mean age of study population being $53.27 \pm 9.22$ years. Twenty patients were found to have positive TMT, most of them belonging to the age group of 48-57 years. The prevalence of asymptomatic CAD in diabetic patients was found to be $26.66 \%$ in our study. Asymptomatic CAD was significantly associated with the duration of diabetes, glycemic control and deranged lipid profile. Conclusion: $\mathrm{T}_{2} \mathrm{DM}$ is an important independent and modifiable risk factor for development of the CAD. TMT is a safe, reliable and noninvasive tool for the timely diagnosis of asymptomatic CAD in diabetic patients. A routine TMT screening for inducible ischemia should be performed in diabetic patients with longer duration of disease, deranged lipid profile and poor glycemic control. Early and aggressive screening of diabetic patients for the evidence of silent myocardial ischemia may prevent catastrophic cardiac events and decrease mortality.

Keywords: Coronary Artery Disease; Type 2 Diabetes Mellitus; Complications; Silent Myocardial Ischemia; Treadmill Test.

Copyright $(\odot 2021$ The Author(s): This is an open-access article distributed under the terms of the Creative Commons Attribution 4.0 International License (CC BY-NC 4.0) which permits unrestricted use, distribution, and reproduction in any medium for non-commercial use provided the original author and source are credited.

\section{INTRODUCTION}

Diabetes mellitus is a metabolic entity characterised by raised blood sugar levels resulting from defect in insulin release, action of insulin or both. It may be accompanied by other biochemical derangements and the presence of progressive diabetic tissue damage with micro and macrovascular complications [1]. Diabetes mellitus is accepted as a worldwide epidemic with an estimated increasing prevalence from $2.8 \%$ in 2000 to $4.4 \%$ by 2030 [2]. It is the most common endocrine disease affecting mankind. The incidence of this disease continues to be on the rise all over the world specially in our country. India is known as "the diabetic capital of the world". It is assessed to have 77 million people influenced by it, with every 6th diabetic person in the world being an Indian. As per International Diabetes Federation's estimation 134 million Indians will have diabetes by the end of the 2045. Cardiovascular diseases are more prevalent in diabetics and is the foremost cause of deaths in patients with type 2 diabetes and is often asymptomatic because of silent myocardial ischemia. The prevalence of CAD in our country earlier varied from $15-65 / 1000$ population, but now it has increased to about 80-120/1000, making it substantial cause of mortality and morbidity [3].

Coronary artery disease (CAD) is multifactorial in etiology and has several important risk factors, out of which diabetes is considered an important modifiable risk factor. CAD manifests itself silently and prematurely in diabetic patients. It has been observed in the Framingham heart study that there is a poor prognosis of cardiac disease in diabetics. Mortality 
related to cardiovascular disease is doubled in diabetic men and quadrupled in diabetic women over that in their non-diabetic counter parts [4]. The association between diabetes and asymptomatic coronary artery disease has been accredited to Autonomic Neuropathy [5]. CAD can be asymptomatic in diabetes and may present itself with sudden cardiac arrest, myocardial infarction, silent myocardial ischemia, arrhythmia, or heart failure. Prompt and early recognition of asymptomatic CAD in diabetes mellitus type 2 patients can prevent catastrophic cardiac events. However, resting ECG and thorough clinical examination may fail to diagnose coronary artery disease. Hence sophisticated cardiovascular non-invasive tests should be proposed for recognition of CAD in these high-risk patients at an early stage.

Exercise electrocardiograph can identify most of the patients likely to have ischaemia during their daily activities and remain the most important screening test for CAD [5]. The aim of this study was to determine the prevalence of asymptomatic coronary artery disease in patients of type 2 diabetes mellitus using Treadmill Test (TMT) and study the relationship between duration of T2DM, $\mathrm{HbA}_{1} \mathrm{c}$ levels and dyslipidemia with TMT changes.

\section{Material ANd Methods}

This observational study was carried out in the Dept. of Medicine between October 2018 to May 2020. Patients ranging from age of 18 to 70 years seeking medical attention, who had been diagnosed with Type- 2 Diabetes Mellitus using ADA criteria (HbA1c $>6.5 \%$, FBS > $125 \mathrm{mg} / \mathrm{dl}$, PPBS > $200 \mathrm{mg} / \mathrm{dl}$ ) undergoing Treadmill Test were included in this study after obtaining a written-informed consent. The exclusion criteria of the study were as follows:

1. Individuals with pre-existing congenital heart diseases, Coronary Artery Disease, Valvular Heart disease, Uncontrolled Hypertension, and unstable angina.

2. Patients with physical disabilities including severe osteoarthritis and others who could not carry out the Treadmill test.

3. Anemic patients $(\mathrm{Hb}<8 \mathrm{gm} \%)$

4. Patients who refused to give written-informed consent for the study.

All the patients included in the study were interviewed about relevant medical history which included duration of diabetes, treatment history and addictions. A general physical examination was carried out, and blood samples were sent for laboratory investigations which included Complete Blood Count, Fasting Blood Sugar, Post Prandial Blood Sugar, Glycosylated Hemoglobin $\left(\mathrm{HbA}_{1} \mathrm{c}\right)$, and Fasting Lipid Profile. A baseline 12-lead ECG was done and 2D Echocardiography was done using Phillips ${ }^{\text {TM }}$ iE33 machine. All the patients were then subjected to a Treadmill Test (TMT) performed on the GETM MAC
5500 Machine using Bruce protocol. Exercise test was terminated in all patients following the achievement of target pulse rate (220 - Age in years) or an unusual ischemic response which was characterized as development of $0.1 \mathrm{mV}(1 \mathrm{~mm})$ of $\mathrm{J}$ point depression with a comparatively flat ST segment slope $(<1$ $\mathrm{mV} / \mathrm{sec}$ ), depressed $\geq 0.10 \mathrm{mV} 60$ to $80 \mathrm{msec}$ after the $\mathrm{J}$ point in three successive beats with a stable baseline. Exercise test was also stopped if patient developed shortness of breath, fatigue, or angina.

\section{Statistical Analysis}

The categorical or dichotomous variables were expressed as absolute values and percentages and were compared with Pearson $\chi^{2}$ test. The continuous variables with a normal distribution were described as the mean (SD). Variables that did not present a Gaussian distribution were compared with the MannWhitney $U$ test. The correlation between two quantitative variables was carried out by using Karl Pearson's/ Spearmen's coefficient of correlation. A p value less than 0.05 was considered statistically significant.

\section{RESULTS:}

In the present study, 75 patients of Type 2 Diabetes Mellitus without any clinical, electrocardiographic and echocardiographic evidence of coronary artery disease were studied. Fifty-seven (76\%) of the 75 subjects were men and 18 (24\%) were women (Figure-1).

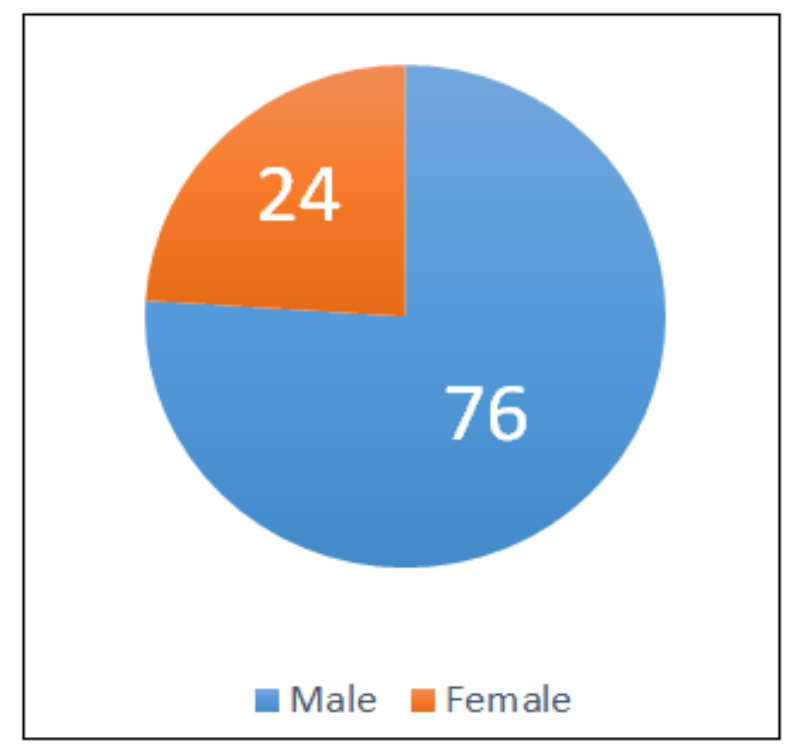

Fig-1: Gender distribution of study population

The mean age was $53.27 \pm 9.22$ years; with a range of 28 to 70 years. Most of the study subjects belonged to the age group of 48-57 years (Table-1). 
Madhur Sharma et al; Sch J App Med Sci, Apr, 2021; 9(4): 512-516

Table-1: Age wise distribution of study population

\begin{tabular}{|l|l|l|}
\hline Age & Frequency & Percentage (\%) \\
\hline $28-37$ & 4 & 5.3 \\
\hline $38-47$ & 13 & 17.3 \\
\hline $48-57$ & 31 & 41.3 \\
\hline Equal and above 58 & 27 & 36.0 \\
\hline Total & 75 & 100 \\
\hline
\end{tabular}

Duration of diabetes less than 5 years was found in 33 subjects (44\%) (Table-2).

Table-2: Distribution of study population as per duration of diabetes mellitus

\begin{tabular}{|l|l|l|l|}
\hline Duration of Diabetes & Male & Female & Total \\
\hline$<5$ years & 26 & 7 & $33(44 \%)$ \\
\hline $5-10$ years & 24 & 8 & $32(42.6 \%)$ \\
\hline$>10$ years & 7 & 3 & $10(13.3 \%)$ \\
\hline Total & 57 & 18 & $75(100 \%)$ \\
\hline
\end{tabular}

The prevalence of TMT positivity in our study was $26.66 \%$ (20 patients, Figure-2) of which majority of subjects $(65 \%)$ belonged to the age group of 58 years and above (Table-3).

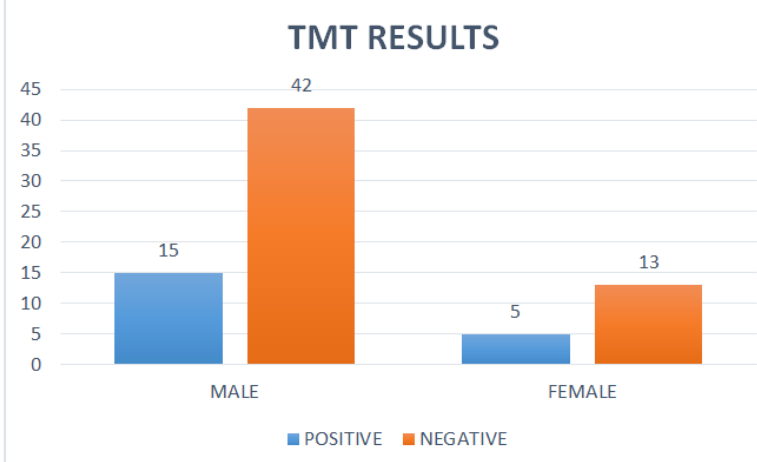

Fig-2: Gender distribution of TMT results in the study population

Table-3: Correlation between age and TMT results

\begin{tabular}{|l|l|l|l|l|l|}
\hline \multirow{2}{*}{ Age } & \multicolumn{3}{|l|}{ Treadmill Test (TMT) } & \multirow{2}{*}{ Fisher's exact test p-value } \\
\cline { 2 - 5 } & Negative & Positive & \\
\cline { 2 - 5 } & Frequency & Percentage & Frequency & Percentage & \\
\hline $28-37$ & 4 & 7.3 & 0 & 0 & \multirow{2}{*}{0.004} \\
\hline $38-47$ & 13 & 23.6 & 0 & 0 & \\
\hline $48-57$ & 24 & 43.6 & 7 & 35.0 & \\
\hline$\geq 58$ & 14 & 25.5 & 13 & 65.0 & \\
\hline Total & 55 & 100 & 20 & 100 & \\
\hline
\end{tabular}

Correlation between duration of diabetes and TMT positivity showed that $65 \%$ study subjects had diabetes duration of 5 to 10 years (Table-4).

Table-4: Correlation between duration of diabetes and TMT results

\begin{tabular}{|l|l|l|l|l|l|}
\hline \multirow{2}{*}{ Duration of Diabetes (years) } & \multicolumn{2}{|l|}{ Treadmill Test (TMT) } & \multirow{2}{*}{ Fisher's exact test p-value } \\
\cline { 2 - 5 } & Negative & Positive & \\
\cline { 2 - 5 } & Frequency & Percentage & Frequency & Percentage & \\
\hline$<5$ & 33 & 60.0 & 0 & 0 & \multirow{2}{*}{} \\
\hline $5-10$ & 19 & 34.5 & 13 & 65.0 & \\
\hline$>10$ & 3 & 5.5 & 7 & 35.0 & \\
\hline Total & 55 & 100 & 20 & 100 & \\
\hline
\end{tabular}

The mean HbA1c of the cases with TMT positive result was $9.82 \% \pm 1.35 \%$ as compared to $8.07 \% \pm 1.34 \%$ in cases with TMT negative result which was statistically significant ( $p$ value $<0.0001$ ). The mean age of cases with positive TMT result was 60.05 years as compared to 50.80 years with negative result which was statistically significant ( $p$ value $<0.0001)$. The correlation between Fasting blood sugar (FBS), Post-prandial blood sugar (PPBS) levels, lipid profile (Total cholesterol, High density lipoprotein, Low density lipoprotein and Triglyceride levels) is described in Table-5.

Table-5: Correlation between age, glycemic control and lipid profile amongst diabetic patients with and without silent myocardial ischemia

\begin{tabular}{|l|l|l|l|l|}
\hline Parameter & Group & Mean & SD & p-value \\
\hline Age & Positive & 60.05 & 5.02 & $<0.0001$ \\
\hline & Negative & 50.80 & 9.27 & \\
\hline FBS & Positive & 191.75 & 53.53 & 0.001 \\
\hline & Negative & 148.40 & 46.08 & \\
\hline PPBS & Positive & 317.00 & 63.93 & $<0.0001$ \\
\hline & Negative & 222.73 & 81.33 & \\
\hline HbA1c & Positive & 9.82 & 1.35 & $<0.0001$ \\
\hline
\end{tabular}


Madhur Sharma et al; Sch J App Med Sci, Apr, 2021; 9(4): 512-516

\begin{tabular}{|l|l|l|l|l|}
\hline Parameter & Group & Mean & SD & p-value \\
\hline & Negative & 8.07 & 1.34 & \\
\hline Total Cholesterol & Positive & 203.15 & 24.64 & $<0.0001$ \\
\hline & Negative & 170.35 & 44.04 & \\
\hline HDL & Positive & 31.65 & 5.10 & $<0.0001$ \\
\hline & Negative & 41.36 & 10.16 & \\
\hline LDL & Positive & 122.20 & 18.69 & 0.004 \\
\hline & Negative & 103.20 & 35.10 & \\
\hline Triglycerides & Positive & 247.85 & 74.09 & $<0.0001$ \\
\hline & Negative & 167.64 & 93.17 & \\
\hline
\end{tabular}

\section{DISCUSSION}

Coronary Artery Disease (CAD) detection in asymptomatic Type $2 \mathrm{DM}$ is often delayed. Silent CAD is an important cause of premature death of diabetic patients. The present study was aimed to detect the prevalence of asymptomatic CAD in the form of silent myocardial infarction in patients of Type 2 Diabetes Mellitus using Treadmill test (TMT). We included 57 men and 18 women as per the inclusion criteria. Out of the total 75 patients TMT positive result was found in 20 patients $(26.66 \%)$ out of which 15 were males and 5 were females and 55 had TMT negative result. The prevalence of silent myocardial ischemia was found to be $26.66 \%$ in patients of Type 2 Diabetes Mellitus. Our findings correlate with other similar studies. Sharda M et al., reported that prevalence of silent myocardial ischemia was $37.3 \%$ in patients of Type 2 DM [6]. In a similar study by Lavekar AS et al., prevalence of silent myocardial ischemia in patients of type 2 DM was found to be $21.1 \%$ [7]. Similarly, Joshi et al., [8] found out that $24 \%$ of patients with type 2 DM without previous history of CAD had positive TMT test. In the present study the mean age was $53.27 \pm 9.22$ years. The patient with a positive TMT test had a mean age of $60.05 \pm 5.02$ years as compared to $50.08 \pm 9.27$ years for negative TMT test, which was statistically significant ( $p$ value $<0.0001$ ). Similar results were reported by Sharda M. et al., in which mean age of TMT Positive and TMT negative were $56.14 \pm 7.71$ years and $51.14 \pm 9.59$ respectively which was statistically significant [6]. In the study by Lavekar et al., the mean age of TMT positive group $(53.56 \pm 7.41$ years) was greater than that of TMT negative group (48.71 \pm 8.72 years) with a statistically significant [7]. Thus, increasing age is an important risk factor for silent myocardial ischemia in diabetic patients. In our study of 75 patients of type 2 DM, 20 were TMT positive for inducible ischemia. 33 patients had diabetes for duration less than 5 years, none had a TMT positive test. 32 patients had duration of diabetes for 5 to 10 years out of which 13 were TMT positive 10 patients had duration of diabetes of more than 10 years out of which 7 were TMT positive. Our findings are similar to other studies in which duration of diabetes in TMT positive cases was significantly higher to those of a negative test $(4.91 \pm 2.51$ years vs. $3.59 \pm 2.13$ year $)$ [6]. Lavekar AS et al., described that the duration of diabetes for TMT positive cases in their study was 6.23 \pm 4.01 years as compared to $3.95 \pm 2.63$ years for TMT negative cases [7]. Joshi et al., reported in their study of 50 diabetic patients that the mean duration of diabetes for TMT positive cases was $13 \pm 4$ years as compared to $9 \pm 5$ years of TMT negative cases [8]. Higher level of $\mathrm{HbA}_{1} \mathrm{c}$ indicates poor glycaemic control which has a significant influence on CAD. In this present study mean $\mathrm{HbA}_{1} \mathrm{c}$ levels of TMT positive and negative cases were $9.82 \%$ and $8.07 \%$ respectively. Statistically significant $\mathrm{p}$ value $<0.0001$ was found in $\mathrm{HbA} 1 \mathrm{c}$ levels of both groups. In the study by Khanapure et al., HbA1c greater than $10 \%$ was found in $44 \%$ TMT positive cases and $45.5 \%$ TMT positive cases had HbAlc of 8.9 to $9.9 \%$ [9]. We found 15 of $20(75 \%)$ patients with TMT positive result and 30 of 55 patients $(54.44 \%)$ with TMT negative result had dyslipidaemia. Among the asymptomatic $\mathrm{T}_{2} \mathrm{DM}$ patients, total serum cholesterol > $200 \mathrm{mg} / \mathrm{dl}$, triglycerides >150mg/dl, LDL levels > $100 \mathrm{mg} / \mathrm{dl}$, and HDL levels <40, had higher prevalence of positive TMT results. Similar results were observed in other studies which found dyslipidaemia was very common in type 2 diabetes and the most common abnormality noted is hypertriglyceridemia (serum TG levels more than $150 \mathrm{mg} / \mathrm{dl}$ ), followed by Low HDL cholesterol levels ( $<40 \mathrm{mg} / \mathrm{dl})$.

\section{Conclusion}

Type 2 Diabetes Mellitus is an important ailment and along with CAD it represents a serious threat to the modern society. CAD has a high prevalence in Asians. $\mathrm{T}_{2} \mathrm{DM}$ is also an important independent and modifiable risk factor for development of the CAD. In our study with diabetic patients having no clinical, electrographic, and echocardiographic evidence of $\mathrm{CAD}$, the prevalence of asymptomatic CAD was $26.66 \%$. TMT is a safe, reliable and noninvasive tool for the timely diagnosis of asymptomatic CAD in diabetic patients. A routine TMT screening for inducible ischemia should be performed in diabetic patients with longer duration of disease, deranged lipid profile and poor glycemic control. Early and aggressive screening of diabetic patients for evidence of silent myocardial ischemia may prevent catastrophic cardiac events and decrease mortality.

\section{REFERENCES}

1. API Textbook of Medicine, 8th Edition. Association of Physicians of India, Mumbai 2008. 
Madhur Sharma et al; Sch J App Med Sci, Apr, 2021; 9(4): 512-516

2. Marín Huerta E, Rayo I, Lara JI, Cuéllar L, de la Calle H, Romero J. Silent myocardial ischemia during Holter monitoring in patients with diabetes mellitus. Revista Espanola de Cardiologia. 1989; 42(8): 519-529.

3. Park K. Park's text book of preventive and social medicine. 18th Ed. Jabalpur: Banarasi Das Bhanot Publishers; 2005.

4. Kahn RC, Weir CG, King LG, Jacobson MA, Moses CA, Smith JR. Joslin's Diabetes Mellitus 14th Ed. Philadelphia: Lippincott Williams and Wilkins Co; 2005.

5. Zipes PD, Libby P, Bonow OR, Braunwald E. Braunwald's Heart Disease, 7th Edition, Philadelphia; WB Saunders company: 2005.

6. Sharda M, Soni AK, Meena S, Nigam H, Singh A. A prospective study on utility of exercise treadmill test in type 2 diabetes mellitus patients. The Journal of the Association of Physicians of India. 2016; 64(11):32-7.

7. Lavekar AS, Salkar HR. Treadmill test to detect stress induced ischemic heart disease in type 2 diabetes mellitus patients asymptomatic for CAD: a hospital based cross-sectional study in rural population of Central India. J Diabetes Metab. 2013; 4(2):1000244.

8. Joshi AS, Lahane CG, Kashid AA. The result of treadmill test in asymptomatic type 2 diabetes mellitus. Int J Sci Rep. 2017; 3(6):166-72.

9. Khanapure SP, Parmar D, Bajaj G, Mural RH. Prevalence of Silent Coronary Artery Disease (CAD) in Asymptomatic $\mathrm{T}_{2} \mathrm{DM}$ - A Prospective Study. International Journal of Contemporary Medical Research. 2017;4(11):2341-5. 